\title{
Photo-Text Topographics: Memory and Place in Sally Mann's Hold Still
}

Christopher Lloyd

c.1loyd@herts.ac.uk

\begin{abstract}
:
This article explores Sally Mann's memoir Hold Still (2015) as a complex photo-text that excavates, mediates and shapes memories, both of her family and the US South more broadly. Theorising photo-text topographics, the article argues that various landscapes (regional, memorative, aesthetic) are mediated by the interrelation between word and image. Mann's depictions of her children, southern location, and — most explicitly—black/white relations in the United States will be shown to reveal how the past can never be "held still."
\end{abstract}

The prologue to Sally Mann's Hold Still: A Memoir with Photographs (2015) begins, almost archetypally, with boxes in an attic, wrapped in twine. These boxes, "detritus left to us by our forebears," as well as "residue of [Mann's] own unexamined past," are of course filled with "snapshots ... by the thousands," among other accumulations. ${ }^{1}$ After being invited in 2008 to give the Massey Lectures at Harvard University, Mann retreats into the attic as though to find solace, or inspiration, in the (traces of the) past. She worries if Harvard would expect her to "justify" the "controversial" pictures she took of her children, in the 1990s, "going about their lives, sometimes without clothing, on our farm tucked into the Virginia hills" (xi), or if she could talk about her later work. Yet, Mann is given free rein to lecture on any topic; her

${ }^{1}$ Sally Mann, Hold Still: A Memoir with Photographs (New York: Little Brown, 2015), ix, x. All subsequent references are noted in-text. 
instinct is to begin "in what William Carlos Williams called 'the local," though she is apprehensive if her tendency is to be "too much local" (xii). In turning to the boxes in her attic, Mann thus confronts both her sense of localism (family, community, place, region) and "the treachery of memory" (xii) that infuses her trove of artefacts. As she writes, "if you want to keep a memory pristine, you must not call upon it too often" as you can "alter it irrevocably" (xii). Here, Mann touches upon a key aspect of memory: its shadow-side of forgetting. Indeed, Mann notes that photography itself is "the malignant twin to imperfect memory" (xiii).

While photography may be thought to "preserve our past" by-in the words of Mann's title, holding things still—Mann argues that contrarily "photographs supplant and corrupt the past" (xiii). In looking at a particular photograph and "remembering" the events or people depicted in it, she writes, "I also knew ... I was forgetting" (xiii). Mann's memoir is continually arrested on this point: can images and writing ever reflect the past, or do they just refract it? And more particularly, how does the past imprint itself on us and the world? In a typical metaphoric flourish, Mann offers an image from nature and language: "When an animal, a rabbit, say, beds down ... the weight and warmth of his curled body leaves a mirroring mark upon the ground"; this "body-formed evidence ... has a name, an obsolete but beautiful word: meuse," which Mann notes is evocatively close to "Muse, daughter of Memory, and source of inspiration" (xiv). Hold Still is Mann's account of these impressions in her own life and work, an attempt to dig into "layers of unknown family history" (xiv). She hopes she will find traces of her own artistic interests in this past ("the fascination with family, with the southern landscape, with death") as well as a "payload of southern gothic," from "scandal" and "aband onments" to "racial complications" (xiv). That the boxes in Mann's attic yield all of this and more should be no surprise. 
This article wants to press upon the flexible mode and form through which Mann excavates, remediates and shapes her memories and southern history and cultural memory more widely. In an article on W.G. Sebald and Monika Maron's “intermedial texts," Silke Horstkotte coins the term "photo-text topography" to define the "spatial dimension which the photos introduce into the linearity of verbal narrative."2 She uses two books by these authors, which include photographs in the writing, to foreground, explore and frame considerations of spatiality. I want to utilise, and slightly adapt Horstkotte's term, and attend to the photo-text topographics of Hold Still, primarily for the ways in which Mann's text mediates landscapes - regional, memorative, aesthetic — and textuality. Topographics, as explored in this special issue's introduction, are aesthetic mediations of the landscape, ways of simultaneously mapping and shaping it. Here, though, I think about physical landscapes and more metaphorical ones (that relate to memory and visuality more broadly). In particular, I think about Mann's memorative topographies, those ways of entwining the past and present in particular landscape images and traditions. Further, I will deviate from Horstkotte's interest in travel and movement (which are so central to the two literary texts she explores) and think instead of the more affective dimensions of Mann's book. The depiction of land scape here, unlike that of the New Topographics for example, is far from stripped back and seemingly "objective"; rather, the South is charged with memory and affect. Of course, the topographic impulse in US photography has often romanticized the nation's landscapes and vistas: we need think only of Ansel Adams or Carleton Watkins before him to see how the United States has been depicted and shaped.

US topographic photography runs from the idealistic to the poetic, from the detached to the cartographic and as explored in this special issue's introduction, are aesthetic

\footnotetext{
${ }^{2}$ Silke Horstkotte, "Photo-Text Topographies: Photography and the Representation of Space in W. G. Sebald and Monika Maron," Poetics Today Volume 29, No 1 (Spring 2008), 50.
} 
mediations of the landscape, ways of simultaneously mapping and shaping it. Here, though, I think about physical landscapes and more metaphorical ones (that relate to memory and visuality more broadly). Mann's sense of place-local, regional, national-transcends these definitions in Hold Still. Ayelet Carmi has similarly suggested that Mann's landscape photographs are simple, but work through "dualisms - personal and national, yearning and rejection, veneration and critique." ${ }^{3}$ I argue, moreover, that it is the enmeshing of image and text, as well as the mediations of landscape that this enmeshing advances, that marks out Mann's book as an important flashpoint in the American genre of topographics. Moreover, joining a long tradition of photo-texts from the twentieth-century, Hold Still is far more than a simple memoir: through the interrelation of word and image, Mann illuminates the multiple topographics of memory and place that saturate her sense of the South.

This article maps some of the ways in which Mann enfolds visual art with words so that the two are inseparable. Rather than the photographs merely illustrating the writing, Mann brings image and text together to form a topography of their own. Following Mann's peripatetic journey into her past, her memories, her artwork, and her version of the US South necessitates following her into a shifting photo-textual topography. In relation to aesthetics, Mann engages with antecedents in Civil War photography and contemporaries like the painter Cy Twombly, where she draws parallels between technologies and processes of image-making alongside regional reflection. In a genealogical vein, the memoir also explores Mann's family and their journeys from and to the US South. But underpinning these dual narratives is the fact of race (especially whiteness and blackness), and the US South's complex relationship to slavery, segregation and other forms of violence. Hold Still's

\footnotetext{
${ }^{3}$ Ayet Carmi, "Sally Mann's American Vision of the Land," Journal of Art Historiography No 17 (Dec 2017), 26.
} 
topographics transcend and transform time and place with an aim to both holding the past still, and seeing it unspool.

To track Hold Still's photo-text topographics, a brief consideration of the photo-text genre will help frame the ensuing discussion. The photo-text is a "project in which writing and photographs are of equal importance," a work "capable of synthesising both writing and photography". ${ }^{4}$ Caroline Blinder here is stressing the interlinked nature of the photo-text, whereby the image element is not mere decoration or illustration, but a central component of the work. Conversely, the writing is not simply an explanation or summary of the image, but a partnered element in meaning-making. Earlier photo-texts like Erskine Caldwell and Margaret Bourke-White's You Have Seen Their Faces (1937) and James Agee and Walker Evans' Let Us Know Praise Famous Men (1941) use photography and literary writing to remediate and re-present versions of the US South in the early twentieth-century. Both books particularly focus on poor and rural southerners, living in harsh landscapes and impoverished locales and both play with the relation of text to image. In the former, captions and essays (written by Caldwell) accompany Bourke-White's more classical photographs, blurring the line between fictionality and reportage. That is, it is unlikely that the subjects of the images said the lines that are quoted beneath them; rather, Caldwell ventriloquises these southerners to render an aural version of the vernacular captured by the visual. In the latter, Evans' photographs preface Agee's writing, so that the reader consumes a set of black and white images — aesthetically beautiful and evocative — before reading the more detailed and engaged text from Agee. As such, in both books (which are considered staples of the phototext genre), the US South is constructed and mediated through the complex interplay between

\footnotetext{
${ }^{4}$ Caroline Blinder, "The Photo-Text in the 19th and 20th Centuries," Oxford Research Encyclopedia of Literature, (June 2017), online.
} 
the visual and written language. Mann's Hold Still, I would argue, continues this trend by splicing together text and image. Indeed, Mann refers to You Have Seen a number of times in the book as a significant influence on her as a young photographer.

The writing in Hold Still, like that of Caldwell and Agee moves from the homey and colloquial — "What kind of dumbass photographer does that make me?" (57)— to the poetic and romantic_- "I took lungfuls of the yeasty, essential smells that came in my open windows, the sweet stink of exuberant fecundity" (226). The richness of the prose is clearly indebted to what Mann sees as a southern literary tradition. And the images in Hold Still range from old family pictures (sometimes displayed with tape or photo-album markings), to childhood drawings, notes, letters, negatives, and even final prints of her adult work. As such, the formal slipperiness that Mann employs - moving from one style and image-type to another-lends the book both an archival, compendia quality, as well as a more elastic sense of how words and images work together. This article focuses on the way that Mann's memoir is as much about image-making and personal history as it is about the fluctuations of memory itself. Moreover, it is the way in which Mann enmeshes image and text that draws out memory's workings. Where Catherine Gander and Sarah Garland note how, in works like this, "words and images have fused, collaborated or met" in order to "advance our comprehension of cultural and intercultural relations," I want to focus more particularly on the role of recollection and place in the US South. ${ }^{5}$ Mann does this simultaneously at a local, familial level, and a wider regional one.

Of course, memory and photography have a deep and fraught connection. In Forget Me Not: Photography and Remembrance (2004), Geoffrey Batchen probes the way in which we often imbue or invest photographs (in particular) and photography (in general) with

\footnotetext{
${ }^{5}$ Catherine Gander and Sarah Garland, "Introduction: To Fasten Words Again to Visible Things: The American Imagetext," European Journal of American Culture Vol 32, No 2 (2013), 116.
} 
properties of helping, enabling or containing memory. Yet, as he asks, "How do you remember? Under what circumstances do you remember?" Can we really suggest that photographs offer a transparent glimpse of the past? Or, "Has photography quietly replaced your memories with its own?"6 Batchen is asking what technologies and frameworks we use in order to remember. For him, photography and the camera have formed a major, yet not always acknowledged role, in shaping how we perceive the past, and even which pasts get remembered in the first place. That is, to what extent do images alter perceptions of our own histories, our families, communities and the broader nation?

Although the slippery relationship between image, text and memory undergird Hold Still — and make possible its aesthetic and emotional work - it is not until about 300 pages in, that Mann foregrounds this relationship more precisely. Describing her father as a young man, she recognises that he now simply "exists as a series of pictures" (301). Thus, rather than a living breathing figure in her past, Mann's father is made up from photographs. As she describes him, with his rolled-up shirt-sleeves, looking thoughtfully and considerately at something nearby, it is not the man she is recalling: "here's the thing: It's a picture, a photograph I am thinking of." Rather than a "memory of the man," Mann has "a memory of the photograph." As she "loses" the "him-ness of him," and clings only to the image-which Mann reproduces in the middle of the page — she states, "It isn't death that stole my father from me; it's the photographs" (302). Thus, photography's relationship to death and loss comes into focus. By keeping her father alive in picture form, Mann's relationship to him becomes less tangible and embodied. The photograph becomes a screen over which the "reality" of the man is papered. Put a different way, in Camera Lucida (1981) Roland Barthes writes: “'myself' never coincides with my image; for it is the image which is heavy,

\footnotetext{
${ }^{6}$ Geoffrey Batchen, Forget Me Not: Photography and Remembrance (New York: Princeton Architectual Press, 2004), 15.
} 
motionless, stubborn ..., and 'myself' which is light, divided, dispersed". ${ }^{7}$ The image freezes and ossifies that which is messy and ever-changing. Glossing Siegfried Kracauer, Batchen notes that photography often "captures too much information to function as memory. It is too coherent and too linear in its articulation of time and space.... Memory, in contrast, is selective, fuzzy in outline, intensely subjective, often incoherent, and invariably changes over time." As such, the photograph of Mann's father in its precision - the shirt-sleeves, his thoughtful look and so on-is the very thing that leads to forgetting. In its attempt to contain and freeze the past, the photograph renders that past less secure by focusing too exactly on minute details.

Tracking the ways that Hold Still frames memory in this way-as embroiled in the mechanics and aesthetics of photography and writing - requires further elaboration of Mann's relationship to her family, then to the southern landscapes in which she's lived, and then more particularly the US South and blackness. Mann is perhaps most famous for the images she made of her young children in Immediate Family (1992). This collection features Mann's children in a variety of settings and poses, often nude, often playing at various roles (smoking a cigarette, pretending to be dead). Numerous critics have pointed out, as Marianne Hirsch notes, the "disturbing suggestions of violence, abuse, and eroticism" in the images, and the ways that "the images touch dangerously on the currently pervasive eroticization of children's, particularly little girls', bodies in American advertising and movies."9 (Of course, Mann's son is as visible as the daughters are, but Hirsch is particularly interested in the way that the girls are caught up in a larger cultural narrative). I do not want to enter the debate around these images - for that is the topic for another essay - but I do want to show how

\footnotetext{
${ }^{7}$ Roland Barthes, Camera Lucia: Reflections on Photography, trans. Richard Howard (London: Vintage, 2000), 12.

${ }^{8}$ Batchen, Forget Me Not, 16.

${ }^{9}$ Marianne Hirsch, Family Frames: Photography, Narrative, and Postmemory (Cambridge, MA and London: Harvard University Press), 152.
} 
Mann pulls in this history to the larger narrative she is weaving in the memoir. While Hirsch suggests that Immediate Family is a "metaphotographic discourse, a commentary and a critique of photographic conventions and ... dominant cultural myths about maternity,"10 Mann herself is more prosaic about the collection, noting that the images are "rooted in our family's domestic routines and our little postage stamp of native soil" (100). Hirsch presses upon the notion that Mann's photographs are part of a larger cultural story about the kinds of images we take in/of families, and how they circulate; moreover, these images are also embroiled in the parental (and specifically maternal) gaze. Hirsch therefore sees the photographs as commenting on how the fantasies of childhood and motherhood are worked through by the public photographs, and how Mann's maternal gaze is underwritten by the aesthetic and artistic one. In contrast, Mann treats the photographs as natural and organic extensions of the rural and enclosed life her family led on the farm in Virginia. The isolation and expanse of the wilderness, a highly American trope, is also a particularly regional one, as Mann invokes William Faulkner's notion of one's "postage stamp."11 The "context of the farm and the cabin on the river-the intrinsic timelessness of the place and the privacy it afforded us" (98) is a rather more rational account of the images than Hirsch's theorization. Either way, though, the centrality of place and the local are at the forefront of Mann's narrative. Even though the children are the central subjects, it is the southernness of the setting that stands out to her and, possibly, to the viewer. The topographies of this collection, as recounted in Hold Still, is one grounded in the South and the family.

Moreover, as in the rest of this memoir, Mann links her photographic process to a longer genealogy of artistic practice and image-making. From Edward Steichen's The Family of Man exhibition and book from 1955-which is playfully repurposed as "The Family of

\footnotetext{
${ }^{10}$ Ibid., 154.

${ }^{11}$ William Faulkner, "William Faulkner: The Art of Fiction," in The Paris Review Interviews, vol. 2 (Edinburgh: Canongate, 2007), 57.
} 
Mann" here - to the work of Bourke-White and Evans, recounted above, Mann traces a photographic topography in which her work nestles. However, there is a big difference between the particularity of the southern images by Bourke-White and Evans, and the global canvas of Steichen's project. The Family of Man gestured to international subjects and settings, rather than local southern (or even US) ones. It is notable that this is one of the few books cited by Mann — other than, perhaps, Marcel Proust later on in regards to the effects and affects of memory - that leaves the US South and particular landscapes for a broader vision. But there are even images such as "Damaged Child" (1984), which "As soon as [she] pictured it," Mann "noticed its kinship with the familiar Dorothea Lange picture 'Damaged Child, Shacktown"' (113). Whether or not Mann had a more conscious relationship in mind between these images, the memoir is an attempt to map out a terrain of artistry that Mann situates herself in. That is, Mann returns again and again to photographers and artists who attempt to depict the US South, and rural American spaces, with a lyrical or emotive vision. Both "Damaged Child" images locate that corporeal injury and vulnerability in a rural setting, underscoring particular land scapes as ripe for sentiment and affect. Moreover, these terrains are marked by particular forms of abuse and marginalization: in Lange's case, this is due to impoverishment and the ravages of the Depression.

Hold Still goes further than simply tracking historical correspondences and also thinks more prosaically about the nature of image-making. For instance, a striking example of Mann's artistic process is her account of the photographing of her son Emmett in a river, "The Last Time Emmett Modeled Nude"(1987). Across a few pages, we see seven different versions of this image, in which the cropping or lighting or pose or angle is not quite right. As Mann takes us through the images, weaving her text between the photographs, as though she is echoing her thinking process at the time, she notes (in the present tense) that "now we're getting closer" to the right photograph: "got the hand s right ... [but] the light is too 
bright" (125). Letting the reader into the world behind the one perfect image, Mann is commenting not only on the shoot itself — how cold the water was, how Emmett said this would be his last nude photograph — but also on the way that the various prints themselves form part of an aesthetic and familial story. These variations of the final image open up a topography of image-making, and also story-making: "The Last Time" is evocative and striking, but it also fixes a moment in time that does not account for the work and process behind it. At play here is the relationship between the personal lives of the Mann family, the broader cultural discourse, and, indeed, the meanings and processes of particular photographs. Yet, this "tumultuous decade, during which the skirmishes of the culture wars spilled into my territory" (134), is, for Mann, ephemeral. The pictures may last in the future, but "All this will be gone. ... but what will last, beyond all of it, is the place" (165). That is, the Virginian landscapes on which these photographs were taken. While, of course, contemporary southern studies would suggest that Mann is simply idealizing a place that exists only in fantasy or narrative - what Scott Romine calls "the Real South," a region that comes into being through cultural reproduction, not any actual essence ${ }^{12}-\mathrm{I}$ would argue that her attention to particular places, and the people that inhabit them, are part of her personal and artistic turn to the local over the national or even global. It is part of her topographic project — and, indeed, the US topographic impulse generally — to detail and delineate certain land scapes and locales with both accuracy and emotion. This is not to say she is not also producing $a$ version of the US South, but that idealization is only one part of her attempt to depict the landscapes around her.

${ }^{12}$ Scott Romine, The Real South: Southern Narrative in the Age of Cultural Reproduction (Baton Rouge: Louisiana State University Press, 2008). 
The turn, in Mann's career, from photographs of her children and family to landscape images can be thought of as a turn from the personal to the social. But in Hold Still, Mann writes that the "gradual move from the family pictures to the landscapes was a shift from what I thought of as our private, individual memories to the more public, emotional memories, those that the past discloses through traces inscribed on our surroundings" (210). The memoir itself seems to blur the lines between the personal and the cultural by moving through broad sections titled "Family Ties: The Importance of Place" or "Gee-Gee: The Matter of Race." As we can see, the familial gives way to the social after the colon - there is no escaping how intertwined the Mann story is with broader issues. The move from the personal to the cultural —in terms of place and memory — can be summarised by Mann's exploration of her family's links to Wales. Her grandfather moved from Wales to the United States, and Mann makes much of the affective connection between the people. "Just like us southerners, Mann writes, "the Welsh are often depicted as nostalgic and melancholic, their heads stuck in the past while pining for hopelessly lost causes" (175). The mythologizing of the Old South, so central to Lost Cause ideology after the Civil War, is linked to the Welsh connection to history and loss. If this romanticising of an already romanticising gesture threatens to de-historicise southern nostalgia, Mann entrenches the point through reference to a Welsh word: hiraeth. This means “"distance pain' ..., a yearning for the lost places of our past”. Moreover, "it always refers to a near-umbilical attachment to a place, not just free-floating nostalgia or a droopy houndlike wistfulness ... [but] about the pain of loving a place" (175).

While Mann runs the risk of essentialising place here (Virginia, the US South), she also distils and evokes this affective relationship to particular landscapes and locales. The body of photographs in Deep South (2005), for instance - in their rich evocation of light and land and texture-emblematise this "umbilical" connection to southern soil. We see, for instance, visceral images of landscapes across the US South, from swamps to ruined 
plantations and dense forests. ${ }^{13}$ In each image, the very earth itself is depicted in a tangible way. Moreover, her earlier childhood images also embody this maternal metaphor, showing children in the dirt, water and foliage — almost birthed from the land itself. Even when excessively gesturing to the "resonant light" in the southern states, Mann is fostering an affective and geographic topographic. Noting how hard it is to take photographs at dusk (especially with the old collodion technique), she notes how the light "appears to have been breathed onto the negative; a moist refulgence within deepening shadows, details dissipating like those in a painting by Turner" (213). Again, linking her work to other artists, Mann also, through the alliteration and sibilance, evokes a photo-textual sense of place. In other words, the physical nature of the collodion process materialises and literalises a very bodily connection to the land.

Another of Mann's first engagements with the landscape of the South is through recollection of the artist Cy Twombly, a close friend of hers. Reflecting, a few chapters previously, on the literal topography of the part of Virginia where Mann grew up and now lives, Hold Still links physical geography, artistic sensibility and temporality. Mann borrows a hoary trope of southernness - that the region is more prone to memory than anywhere else- but grounds this through her association with Twombly. The painter lived "half the year in Lexington, his hometown," which is, for Mann, "a testament to the allure of the area": Rockbridge County (63). Referencing the art critic David Sylvester, himself citing the artist Paul Klee (the artistic forefathers stack up in this book), Mann agrees with Klee that artistic creation is "analogous to a tree's growth" (63). She takes this as proof that Twombly's aesthetic and productivity are rooted in the literal Virginia soil. Among other influences on his work, Mann mentions “the blaze of southern light on Lexington's columned buildings, its

${ }^{13}$ I have discussed this collection in more depth in Rooting Memory, Rooting Place: Regionalism in the Twenty-First-Century American South (New York: Palgrave Macmillan, 2015), 85-116. 
cultural grace and languor, the region's literary heritage, its pervasive sense of faded grandeur and venerated historical myth" (69-70). Here, Mann again taps into a dubious mythologization of the South.

A little later in this chapter, Mann both describes and shows one of Twombly's photographs; it uncannily echoes Mann's own images, which she acknowledges. The image is of nothing discernible: we see hazy mauves and whites bleed into one-another, it is deliberately abstract. She writes, very poetically here, that Twombly's photographs are "hazy and casually indifferent to detail - this is not eidetic memory; this is the way our minds recall and our hearts remember. They have a misty luminosity, perhaps the mists of time or the forgiving scrim of recall" (84). Here, at the word "recall," Twombly's photograph interrupts the text and manifests a kind of hazy remembrance on the page. While the image is partly an example of the style Mann describes, it is also a visible interruption into her writing. It is as if the emphatic literariness of her sentence transforms into image. Below the picture, she goes on to say that Twombly "made these pictures not with a sharp Proustian vision but with an eye veiled by the famously thick, characteristically humid southern air." Their "part of the South" is "patinaed with the past" and thus enables them "such a remove, the distance of another time" (84). As this section of the chapter ends, the blur of memory and aesthetic strategy collapse due to the enlacing of word and image - the latter interrupting the former, the two elements reflecting on each other. The picture enhances and muddies Mann's prose so that the reader must traverse the topography of remembrance and southern exceptionalism that she is creating. Hold Still produces what Katherine Henninger calls a "visual legacy of southern culture," a continuum of narratives and images that construct what we think of as the South. ${ }^{14}$ In a way, Mann adds to "the intricate web that constitutes our knowled ge of the

\footnotetext{
${ }^{14}$ Katherine Henninger, Ordering the Façade: Photography and Contemporary Southern Women's Writing (Chapel Hill: The University of North Carolina Press, 2007), 1.
} 
South, the 'great dialogue' that is the regional culture."15 This "web of words" as Richard

Gray calls it, is the ongoing work of writers and other artists to depict $a$ South, in conversation with others. The US South, in this way, is a construction or amalgam of the region's variations and remediations.

One of Mann's key imaginings of the region is her exploration of the southern states, from Virginia down to Mississippi and Louisiana. We see this in the memoir's narrative journey from the family to the South, but also in her gradual movement deeper into the region through her photographic exhibitions and books. At first, Mann travelled around her home state, visiting rural spaces that clearly had a connection to the Civil War. Photographing empty fields - to visualise those "encoded, half-forgotten clues within the southern landscape" (210) - Mann reaches back into history to show how saturated the US land scape is with the past. Moreover, Mann not only traverses southern topographies, but travels back to a different photographic medium: wet-plate collodion. It was created in the mid-nineteenth century as a replacement to the daguerreotype, and requires wet plates, various liquids and solutions, and a mobile darkroom. The process requires swift work, but in her van, Mann is able to immediately and evocatively image the land scape on site. The visual distortions you see on the pictures are the result of the collodion process and its "imperfections." Mann makes the most of these physical scratches and blurs, in addition to the flecks of dust, mud, leaves and finger-marks that get on the plates. Collodion has a twofold import here: firstly, it connects Mann to a photographic past, linking the images of the land scape to those that precede them; secondly, it foregrounds and self-reflexively calls attention to the images' own making and maker. But more than this, the work gestures back to earlier American photographers like Matthew Brady who defined (with his team) the very nature of war photography in the nineteenth century. His

\footnotetext{
${ }^{15}$ Richard Gray, A Web of Words: The Great Dialogue of Southern Literature (Athens: The University of Georgia Press, 2007), 10.
} 
collodion images, exhibited as The Dead of Antietam in 1862 in New York, are clearly precursors to Mann's own. The photographs in this exhibition brought the horrors of the Civil War directly to the attention of those living far away from its battlefields. Haunting images of dead bodies, littered across open terrains, highlighted both the magnitude of death and the particularity of certain lives lost during the war. Mann's photographs of those same terrainsevocatively shot with the same artistic medium — cannot but, in their attention to the affectivity of certain landscapes, recall Brady's. By utilising and re-working an artistic form of imagemaking that has particular precursors in this landscape, Mann's topographic work is thus both aesthetic and historical. By using the same technology as Brady, Mann's art becomes both timeless and anachronistic - both in and out of time.

Mann goes further, though, and suggests a kind of deathly topographic impulse: "does the earth remember?" she asks. "Do these fields, upon which unspeakable carnage occurred, where unknowable numbers of bodies are buried, bear witness in some way?" (411). Beneath these perhaps overwrought questions is a striking black and white image, as though answering Mann's queries. It is very dark, but we see a horizon line, lit up with sunlight and flecks of dirt or dust. This simple image, which is almost scored through the middle by the bright band of light (amidst almost complete darkness), is Mann's aesthetic way of showing the reader how the earth might remember. In other words, the collodion image demonstrates her topographic impulse of investing the landscape with affect, evoking such emotions through the way in which the land is depicted. While Mann's topography actively remediates the land scape around her, through photographic technique and aesthetics, it also operates graphically as a way to rupture the coherency of the image itself, to signal that it gestures towards things that cannot necessarily be captured.

Even looking at such "an ordinary landscape," Mann writes, she "also see[s] the underpinnings of death" (414). And earlier in the book, Mann charts a journey-that she told 
more fragmentarily in the collection Deep South - further south (geographically), to find more history (regionally). Noting that many in the South have preferred "not to acknowledge the abiding human spirit of slavery" (279), Mann also states that the region is "haunted" by the African Americans who toiled its land and built its economy, culture and society. This gothic trope of haunting and ghostliness is, in Mann's writing and photographs, a way of registering the violence and trauma that occurred in these landscapes. Visiting the Tallahatchie River, where Emmett Till's body was dumped, and other antebellum ruins and buildings, Mann builds a southern topographic that-through poetic language, personal meditation, and aesthetic play — tries to engage the racial legacies of the region that she is so tied to. The "pain of loving a place," or hiraeth, also involves reckoning with those aspects of it that are hard to face and, perhaps, thus harder to capture photographically.

Part of Mann's unpacking of the US South's relationship to race - in romantic, nostalgic and mythic terms - is a whole section about race-relations and her family's maid Gee-Gee. The section "Gee-Gee: The Matter of Race" is Mann's attempt to reckon with her personal and cultural relationship to whiteness and blackness, especially as they play out in the US South; as discussed above, the familial, regional and the national are so entwined. In this section we see two important images of Gee-Gee $(241,243)$ : in both, she is smiling - the first is a close up, and the second is a long-shot, with Gee-Gee holding a baby that we presume is a very young Sally. Mann addresses the figure of her childhood maid by writing, "Down here, you can't throw a dead cat without hitting an older, well-off white person raised by a black woman" (243). Down here indicates the purported southernness of the story she is about to tell, but this is followed by an acknowledgement that the "fund amental paradox of the South" is that a white elite, who are fervently trying to keep the races separate (through social, legal, cultural and violent means), also deeply depend on black labour in their very homes, to raise 
children and tend to the house. As Grace Elizabeth Hale has written, "Racial identity within the culture of segregation depended in more ways than one upon the symbolic power of the mammy—being white meant having black help."16

Thus, the tension here is the consolidation of whiteness through bringing into proximity, and keeping at a distance, blackness. Yet, Mann notes that "no matter how many historical demons stalked that relationship" she loved Gee-Gee "the way other people love their parents" (243) and vice versa. Though Mann is not the only privileged white writer to recall (and narrate) this relationship fondly, she does press further asking, "What were any of us thinking? Why did we never ask the questions?" and "That's the mystery of it —our blindness and our silence" (259). Writing here of the family's unknowingness, or unwillingness, to know anything about Gee-Gee's real life, the questions are inherent to any deeper interrogations of race and memory in the US South. Tellingly, these quoted lines appear on the page beneath a photograph of Gee-Gee, in which she is hanging laundry on the line in the garden, looking back at the person taking the image. It is as though, even when Mann is trying to rethink her relationship to black servitude, those questions sit beneath the black woman doing domestic labour. And, of course, it is notable that Gee-Gee's story is only told from Mann's white perspective; she herself is denied a voice in the memoir. This understandable absence nonetheless rescripts the dynamics of power in which only certain voices get to ask questions about the complexities of race.

If the focus on Gee-Gee is an attempt by Mann to atone for her family's unquestioning employment and disconnect from a black woman, the next part of Hold Still, which thinks more broadly about the role of slavery in the US South, leads Mann to a new photographic subject. In trying to address the lack of explicit markers to slavery - an issue that has gained even more

${ }^{16}$ Grace Elizabeth Hale, Making Whiteness: The Culture of Segregation in the South, 18901940 (New York: Vintage Books, 1999), 103. 
relevance in recent years, after the removal of Confederate statues, the tragic events of Charlottesville, and, more productively, after the construction of museums about slavery and lynching in Louisiana and Alabama-Mann has turned to photographing black men. This is significant as her photographic oeuvre has always been located outside, in the "natural" land scape, whereas this particular work is moved in to the studio. We might argue that Mann's grasp of black history and the black US South needed a form of embodiment that external and natural topographies could not quite capture; rather, it is to physical African American subjects that her attention has focused.

“The first picture of a black man I took was easy," Mann states. This awkwardly simple line is accompanied by the image, showing mainly a man's back. We cannot see any particular features of the man — definitely not his face-but we can trace, perhaps, a scar on his back. The mark could be any number of things (the evidence of injury, a fresh cut, or even dust on the collodion plate), but it is the tiny element that stands out - not quite a punctum, for it is surely too visible to any viewer. While taking the photograph may have been easy, Mann's language — "This freak of a good picture" (281) — not only risks abjecting the subject through the word-choice of "freak," but also stripping him of any life or role in the image-making process. Mann's language turns again to a different register when she tells us about the "models" who come to her house, almost all of whom are "strangers." "When they walk into my funky-ass studio," Mann writes, as though evoking a kind of street slang, the men "are guarded and suspicious ... Who is this grey-haired old gumboil[?]" and "what kind of pictures does she want?" (284). It is notable that Mann's language changes in this section, employing colloquialisms and tonal shifts, as though to account for or register the black men who are now in her studio (and, indeed, within the memoir itself - their bodies interrupting the flow of text). Moreover, where in the other sections of the memoir, Mann speaks on behalf of Gee-Geethinking about her life and experiences-here she actively voices her photographic models. 
Rather than actually quoting these men, or asking them actual questions, she conjectures as to their inner thoughts, even vocalising particular vernaculars. Mann's engagement with actual black people (from the past and present) is frequently rendered through ventriloquism that is troubling.

Yet the question "what kind of pictures does she want?" speaks most precisely to the historical, aesthetic, regional, and memorative topography that Mann is charting in her phototext memoir. For, like the images of her children years before, the images of anonymous black men touch upon relationships of power and subjectivity, as well as eroticism, violence and intimacy. All of the images are highly corporeal, focusing often on the men's backs or arms or chests. This choice is clearly rooted, for Mann, in the way that slavery hinged on the uses and abuses of black people (and their bodies): "It's the body that's being offered for sale, bought and sold. It's the body that divides us" (286). Though even here the repeated depiction of the abstract body seems to reinforce, rather than unpick, the problematic connection between blackness and embodiment that has lingered in the US imagination. The physical nature of the topography within the intimacy of Mann's studio may be vastly different from that of the inscribed land scape noted earlier, but in some ways both are intent on registering the ways in which race continues to linger in the US imagination. Displaying a range of these photographs across a double-page spread, Mann intersperses them with lines of poetry from Walt Whitman about the human body and its complexity. Again, Mann links her project to a larger American genealogy, but there is also a strange play here between blackness and whiteness, the high art of Whitman and the nameless flesh of these black men. Moreover, Whitman's poetry is as keenly erotic as it is romantic; much of Leaves of Grass (1855-) focuses on the physicality and sensuality of the male body, and Mann must be aware of this.

Thinking about such eroticism, when people ask her about this project, Mann writes, they immediately invoke Robert Mapplethorpe. "No, not like Mapplethorpe. Not at all like 
Mapplethorpe" (289), she resists. But even this fervent disavowal which, in its repetition, reads too clearly as defensiveness, a link is drawn between these images and those infamous depictions of black male bodies. Kobena Mercer's influential essays on Mapplethorpe's images, collected in Welcome to the Jungle (1994) brings the tension inherent in the images into focus. He sees those photographs not simply as the product of the photographer but as "a cultural artefact that says something about certain ways in which white people 'look' at black people and how, in this way of looking, black male sexuality is perceived as something different, excessive, Other." ${ }^{17}$ While I would say that the sexualisation or eroticism of Mann's images is in a very different tenor to those of Mapplethorpe, the sense that the pictures take part in a larger discourse of blackness and whiteness, of seeing or being looked at, the artist and the subject, is undeniable. As George Yancy writes, to consider visual representations of black bodies, we need to "capture the current and historical epistemic and habituated embodied orders that configure and sustain the white gaze and function to objectify the Black body as an entity that is to be feared, disciplined, and relegated" to various social spaces and positions. ${ }^{18}$ That is, the white gaze on the black body cannot but be situated in dynamics of racist power from the American past and present: there is no neutral look. In other words, all depictions of black bodies by white image-makers bring with them historical and cultural baggage, freighted by racist imaginings and material dispossession in the past. Mann's depictions have to be seen in this light.

Mann's memorative topography — gesturing back into the past of photography, of the US South, of the landscape, and of art-reaches its problematic apex in this project of photographing black men. For, in connecting slavery, the South, Gee-Gee, the landscape,

${ }^{17}$ Kobena Mercer, "Reading Racial Fetishism: The Photographs of Robert Mapplethorpe," in Welcome to the Jungle: New Positions in Black Cultural Studies (London and New York: Routledge, 1994), 173.

${ }^{18}$ George Yancy, Black Bodies, White Gazes: The Continuing Significance of Race in America, 2nd ed (Lanham, MD: Rowman and Littlefield, 2017), xxx. 
collodion, and the body, it seems to materialise the logic of Mann's aesthetic and imaginative project all along. Describing the interaction between her and the sitters, Mann writes: "We don't speak much, but we both give, and take, something. At the most basic level, making these images is exploitive, reductive, and fraught. But at a higher level, which portraiture at its best can achieve, the results can also be transformative expressions of love, affirmation and hope" (293). That is, even when the relationship between these black men and this white woman, in the US South, is undergirded by centuries of suffering and exploitation, Mann argues that the photograph can transcend and unmoor itself from the past. She asks, can the session of photographing "bridge the seemingly untraversable chasm of race in the American South?" (293). Can photographs, in this instance, yoke the past and present, black and white? Does the acknowledgment that these new images express Mann's "belated thanks" to Gee-Gee and the other black people that sustained her childhood and life in Virginia really do anything politically transformative?

Hold Still attempts to address and redress the past - it tries to link the past to the present, offering a topography that knows few temporal bounds. But when it comes to the racial politics at the heart of the Mann family_ and at the heart of their home and regional landscape — the effort to depict and describe it only serves to replicate and reproduce power-structures from that past. History and memory are not so simple. And while Mann would likely agree with this last statement, it would probably be for very different reasons. Where Hold Still and the series of photographs of black men are, in part, Mann's attempt to apprehend and work through historical injury and familial exploitation, neither the images themselves nor Mann's prose about them reckon enough with the dynamics of power at play. Anonymous - and frequently faceless - black men are reduced to their bodies, a kind of brute corporeality, which is then transformed into aesthetic beauty. The long histories and memories still attached to such a visual project - through blackface, lynching photographs, The Birth of a Nation, and so on- 
cannot be disarticulated merely through visual pleasure. The past lingers in these photographs, but not necessarily in the ways that Mann intends.

The title of Mann's memoir is both an imagined injunction to a photographic subject, as well as the fantasy of photography's ossifying power. The stillness of an image - the way it purports to hold a single moment in its grasp — belies the fact that no matter how immobile the photograph's subject, it keeps on changing. On the cover of the hardback edition, we see a girl, who we presume is Mann herself, somehow suspended in mid-air, backed by clouds and a vast sky. With no context to ground the child, she is free-floating and effortlessly still. Yet, the movement required to get her into this pose is disavowed by the image and the intention behind it. This relates to a letter that Mann recounts, from the time when she was photographing her child ren for Immediate Family: "You wait for your eye to sort of 'turn on,' ... clenching teeth and whispering to Jessie [her child] to holdstillholdstillholdstill and just knowing that it will be good"(129). Mann's repetition of hold still, as a kind of refrain, underpins her knowledge that if only things remain static then the picture "will be good." As Barthes puts it in Camera Lucida, "What the Photograph reproduces to infinity has occurred only once"; but it also embodies "the return of the dead." 19 The tension here is that the photograph takes a moment that was only very fleeting but makes it static and reproducible. In a related way, the photograph brings the dead back, points to the thing that has gone (which once transpired, if only briefly), and allows it to live on. Barthes pushes this point arguing - contra Mann — that "The Photograph does not call up the past (nothing Proustian in a photograph). The effect it produces upon me is not to restore what has been abolished ... but to attest that what I see has indeed existed." ${ }^{20}$ In this sense, photographs do not resurrect

${ }^{19}$ Barthes, Camera Lucida, 4, 9.

${ }^{20}$ Ibid., 82. 
the dead so much as testify to the once living. This emphasis on what was is also considered by Mann’s memoir. By digging into her family, community, region, and nation's pastacross landscapes, and through words and images_-Mann tries to hold something still. Conversely, though, the shifting photo-text topographies of Hold Still continually move and change. Far from keeping the past or present intact (in place, still), the memoir's enlacing of text and image keeps history and memory in motion. The memoir, and this article, began with Mann's interrogation of memory and forgetting's complex duality: too much of the former may lead to the latter; too much of the latter and memory will inevitably bubble up. Mann's memoir is both a personal reflection and an aesthetic investigation into this complex world of recollection. In Mann's South, photographs do call up the past, but it never holds still.

\section{Author bio:}

Dr Christopher Lloyd is a Lecturer in English Literature at the University of Hertford shire. He is the author of two monographs, Corporeal Legacies in the US South: Memory and Embodiment in Contemporary Culture (2018) and Rooting Memory, Rooting Place: Regionalism in the Twenty-First-Century American South (2015), as well as numerous articles and chapters on various aspects of contemporary US culture. He is Reviews Editor for the European Journal of American Culture and the founder/organiser of the Southern Studies in the UK Network. Christopher's current projects include a new book called American Animals and an edited collection on affect and pedagogy in literary studies. 